\title{
Measurement of Air Flow Around an Inlet Valve using a Pitot Probe.
}

\author{
Mr A White \& Dr M.A.Passmore \\ Loughborough University
}

Copyright () 1998 Society of Automotive Engineers, Inc.

\begin{abstract}
This paper describes a detailed study into the use of a pitot probe to measure air flow around an inlet valve under steady state conditions. The study was undertaken to assess the feasibility of the method for locating areas of a port and valve which may be contributing to a poor overall discharge coefficient. This method would provide a simple and cheap experimental tool for use throughout the industry.
\end{abstract}

The method involves mounting a miniature internal chamfer pitot tube on a slider attached to the base of the valve. The probe can traverse the appropriate area by rotating the valve and moving it along the slide. Changing the probe allows measurements in different planes, allowing the whole region around the valve to be surveyed. The cylinder head complete with instrumentation is mounted on a steady flow rig.

The paper presents the results obtained at different valve lifts on a production cylinder head. The effect of pitot tip orientation is discussed and the integrated mass flow compared with that obtained from an air flow meter. The method is shown to work well for low lifts prior to the point where tumble is initiated. The method is used to reveal the change in flow due to a port modification responsible for a small reduction in discharge coefficient.

\section{INTRODUCTION}

Recent progress in automotive engine design has focused on the structure and formation of the combustion process. Although there are many methods of measuring air flow into a combustion chamber, many of these techniques require expensive instrumentation and permanent modifications to the cylinder head.

A widely used test method for the design and analysis of ports and valves is the steady state air flow rig. ${ }^{1}$ The rig consists of an air supply and throttle, an air flow meter and a plenum chamber. The cylinder head under test is mounted on the output of the plenum chamber and the mass flow through the valve determined over a range of valve lifts while a constant pressure is maintained across the head. See Figure 1.

\section{Figure 1 Schematic of steady flow rig}

Results obtained from such a rig indicate the overall performance of a port and valve combination as a complete unit. This is usually shown as a plot of valve discharge coefficient against non-dimensional valve lift. However as the method does not provide detailed flow field information it cannot be used to determine areas of good or bad flow. Interpretation of the results relies on the experience of the engineer involved and the information which can be inferred is limited.

This paper considers the application of a simple pitot probe to measure the flow at positions around an inlet valve. In particular within the core jet flow. The method is not put forward as an alternative to LDA, hot wire or similar methods, but rather as a straight forward, low cost, addition to a conventional steady flow rig, capable of providing sufficient flow field information to allow a head design to be refined.

A series of investigations were undertaken to examine each factor effecting the use of a pitot tube to measure the air flow. The work is considered in two stages. The initial studies investigate the general suitability of the method. This work includes:

- effect of probe tip yaw orientation with respect to the valve and port position

- effect of valve lift

- effect of flow blockage

- repeatability of the method.

In the subsequent work the method is applied to a standard and to a modified cylinder head. Circumferential traverses in a number of planes were performed to map the flow around the valve, and the results are discussed. The integrated mass flow is compared with that obtained from the airflow meter. The modified head incorporates a small port defect and the results are compared with the unmodified version.

\section{GENERAL METHOD}

A single pitot probe is made from small diameter $(0.8$ $\mathrm{mm}$ ) tubing. The tip was internally chamfered since this 
type of pitot head has been shown to be the least sensitive to yaw. ${ }^{1}$ In addition the tip was kept ten tube diameters away from the first bend in the tube to optimise the tip total pressure reading. ${ }^{2}$ The probe was then held in a small slider which attached to the base of the valve away from the jet-stream of incoming air. (Figure 2.) By changing the probe stem length, and by rotating the valve with the slider attached an annular shaped region can be traversed.

\section{Figure 2 Pitot probe arrangement on base of valve.}

During steady state tests the cylinder sleeve is usually fixed to the cylinder head. This would make access to the valve and slider mechanism difficult and slow. In this case the sleeve is therefore mounted on an adapter which allows it to hinge and ensures that it relocates in the same position each time. This allows readings to be taken quickly.

Throughout testing the fan and throttle were controlled to maintain a constant pressure of $250 \mathrm{~mm} \mathrm{H}_{2} \mathrm{O}$ across the cylinder head. Pressure readings were made using a manometer referenced to the upstream plenum static, this gave consistent results under varying atmospheric conditions. An accuracy of approximately $1 \%$ of the total (i.e. $2.5 \mathrm{~mm} \mathrm{H} \mathrm{H}_{2} \mathrm{O}$ ) is estimated for the instrumentation employed.

A 16 valve cylinder head was used for the purpose of this investigation. Although the investigation was made around a single valve, both valves were opened to simulate the intake stroke.

\section{INITIAL STUDIES}

Since the accuracy of the readings may depend on the probe orientation a series of investigations were undertaken to observe the pressure reading at various pitot tip yaw angles. The slider was mounted to a perspex wedge which was milled at $5^{\circ}$ increments as shown in

Figure 3. The arrangement used ensured that the probe was rotated about the tip such that the measurements were always made at the same point in the flow.

\section{Figure 3 Arrangement for yawing probe tip.}

The probe tip was kept in the middle of the jet stream and a single rotation of the valve was made for each yaw orientation throughout the valve lift range. The results are shown in Figure 4 which represents the tip orientation which yields the highest pressure reading as a function of valve rotation and lift. In obtaining the results in this figure the pitot was found to be much more sensitive to orientation than indicated in the literature for a probe in unconfined flow. The tests indicated that a $1 \%$ change (with respect to total) in reading occurred for changes in yaw of less than $5^{\circ}$.

\section{Figure 4 Optimum tip orientation.}

There are two distinct features in Figure 4. The flat bed of the plot shows that a pitot tip yaw of approximately $45^{\circ}$ gave the highest reading of the total pressure up to 5 $\mathrm{mm}$ valve lift. However, above $5 \mathrm{~mm}$ lift the second feature on the plot shows a steep valley indicating that the radial flow has broken down and that the air passes over the back of the valve. This type of flow is required for the generation of tumble and marks a limit for the use of the pitot probe. It is also noted that the optimum tip orientation coincides with the valve seat angle. Combined with the earlier finding that the probe is sensitive to yaw angle this would suggest that there is a significant blockage effect.

The blockage effect of the tube was crudely investigated by making a series of measurements with varying sizes of probe the smallest of which had a diameter of $0.5 \mathrm{~mm}$. Probes with larger diameters up to $3 \mathrm{~mm}$ were also tested. Over this range the variation in total pressure was $\pm 1 \%$. Smaller probe sizes were not available to allow a further study of the blockage effect. For ease of manufacture a tube diameter of $0.8 \mathrm{~mm}$ was used for all subsequent measurements.

Since a high tumble cylinder head was used with a very short throat length, the flow may also have a component dependent on the port axis angle. The pitot tip was therefore rotated with respect to the valve stem as shown in Figure 5.

\section{Figure 5 Tip rotation with respect to valve stem.}

However the total pressure was maximum at zero degrees with respect to the valve stem. Indicating that the air flow was primarily radial up to the valve lift associated with initial tumble generation.

Repeatability of the method was addressed on two counts. The first considered the effect of test set up and was determined by a complete strip down and rebuild of the rig. The variation in total pressure was found to be of the order of $\pm 1 \%$. The effect of day to day changes in ambient conditions were accounted for by correction and the use of a reference pressure.

\section{EXAMPLE INVESTIGATION}

The practical implementation of the method was assessed by an investigation on a standard 16 valve cylinder head. A valve opening of $3 \mathrm{~mm}$ was selected as it is well below the lift at which tumble is initiated. Both inlet valves were opened. The flow was traversed in an annular region around the valve defined as follows:

- Radially at $1 \mathrm{~mm}, 2 \mathrm{~mm}$ and $3 \mathrm{~mm}$ from the valve edge.

- Circumferential in 10 increments.

- In three planes level with the base of the valve and 1 $\mathrm{mm}$ and $2 \mathrm{~mm}$ below this.

The compact nature of the head meant that one side of the valve was very close to the cylinder liner. Clearly this 
region cannot be accessed and contributes little to the overall flow. In the subsequent plots of results these regions are shown as having no data.

In total the traverse required approximately four hundred data points, these could be gathered in a little over two hours. The results are plotted in Figure 6 . The schematic Figure 7 indicates a number of specific points of interest. The contour values are the approximate local flow speed.

\section{Figure 6 Standard head, three plane traverse.}

\section{Figure 7 Areas of note on Figure 6}

1. The jet stream issues from the valve, dispersing as it passes through the planes. A majority of the air flows over one half of the valve. This is a result of a high tumble cylinder head being used for this investigation.

2. The flow is accelerated close to the cylinder liner.

3. Flow disturbance was measurable at the spark plug tip.

4. A large volume was occupied by the cylinder head casting and received no subsequent data value.

The region of interest was then extended to planes a distance of one and two millimetres upstream of the valve base; between the valve and seat. These results are shown in Figure 8. The two upper planes show an increase in the size of the highest pressure regions.

\section{Figure 8 Standard head, five plane traverse.}

The total mass flow for each plane was then calculated by integrating the individual readings and compared to the mass flow rate determined from the flow meter $(0.031 \mathrm{~kg} / \mathrm{sec})$. As the measurements have only been made around a single valve it is assumed that there is equal flow through the two inlet valves. The calculation is therefore only included as a guide to the method. The first column of data is the integrated mass flow rate (integrated), and the second column is the ratio of the integrated mass flow rate to that determined from the flow meter (ratio).

\begin{tabular}{|l|l|l|}
\hline Plane & Integrated & Ratio \\
\hline $\mathbf{2 ~} \mathbf{~ m m}$ downstream & 0.0260 & 0.839 \\
\hline $\mathbf{1 ~} \mathbf{~ m m}$ downstream & 0.0297 & 0.958 \\
\hline Level with valve & 0.0305 & 0.984 \\
\hline $\mathbf{1 ~} \mathbf{~ m m}$ upstream & 0.0335 & 1.081 \\
\hline $\mathbf{2 ~} \mathbf{~ m m}$ upstream & 0.0405 & 1.306 \\
\hline
\end{tabular}

The table shows that moving upstream from the traverse level with the base of the valve the mass flow deficit increases as the jet flow becomes less well defined.
Upstream of the valve base the integrated result yields a higher mass flow than the flow meter. This is attributed to a stagnation region on the back of the valve, ${ }^{3}$ and to the use of a pitot probe rather than a pitot static.

\section{COMPARATIVE TEST ON A MODIFIED PORT}

To assess the use of the method for examining the cause of small reductions in discharge coefficient the standard head was modified and re-tested. A small piece of modelling putty $(5 \times 5 \times 2 \mathrm{~mm})$ was smeared up the inside of the port at a position of moderate flow. The modification is representative of typical variation in port manufacture. The cylinder head was then subjected to a standard steady state air flow test and a repeat of the three downstream planes of pitot probe readings. In both cases these were conducted at three millimetres of valve lift.

The standard steady flow tests showed that the modification resulted in a reduction in mass flow rate from $0.0310 \mathrm{~kg} / \mathrm{sec}$ to $0.0307 \mathrm{~kg} / \mathrm{sec}$. Corresponding to a change in discharge coefficient from 0.330 to 0.323 . The result from the traverse is shown in Figure 9. The schematic labels areas of interest.

\section{Figure 9 Modified cylinder head - three plane traverse.}

Comparing Figure 9 to Figure 6 the reduction in flow in the region of the modification can be observed (point 1 ). A localised flow rate analysis confirmed that this is responsible for the overall reduction in flow.

\section{Figure 10 Areas of interest on Figure 9}

There are further discrepancies occurring away from the modification. The change close to the spark plug is due to its removal and re-fitting such that the electrode tip was orientated differently. There is also some variation on the opposite side of the valve to the modification. These changes do not account for significant differences in overall flow rate, but highlight the limited nature of the method being used.

\section{CONCLUSIONS}

- A simple small pitot probe can be used to make basic flow field measurements around an inlet valve.

- Measurements must be restricted to low lift, defined as that prior to which tumble generation is initiated.

- Traverses should be conducted at or downstream of the plane subscribed by the valve base. Above this measurements may be influenced by the stagnation region on the back of the valve.

- The method has been shown to be able to locate a flow disturbance responsible for a $1 \%$ change in mass flux.

- The method provides an inexpensive and adaptable way to analyse flow changes, allowing an engineer to optimise a port and valve combination. 


\section{ACKNOWLEDGEMENTS}

This paper is the result of work undertaken as Andrew Whites final year undergraduate project. Assistance was received from many sources but the Authors would like to thank two people in particular. Graham Irlam of Tickford Ltd, England, who originated the project and supported it throughout; and Derek Harkis of the Department of Aeronautical and Automotive Engineering and Transport Studies for his assistance in manufacturing the test rig and probes.

\section{REFERENCES}

1. Boer $\mathrm{CD}$ et al, Refinement with performance and economy for four valve automotive Engines. I Mech E paper C394/053

2. Ower E, Pankhurst RC, The measurement of Airflow.,5th edition, pub: Pergammon. 1977.

3. Jones P, Junday J, Full Cycle Computational Fluid Dynamics Calculation in a motored Four Valve Pent-Roof Combustion Chamber and Comparison with Experiment. Society of Automotive Engineers, Paper SAE950286, 1995. 